\title{
Jogo e deriva com mídias (des)locativas
}

Playing and drifting with (dis)locative media

\author{
David M. Sperling \\ Universidade de São Paulo, Brasil \\ sperling@sc.usp.br \\ Fábio Lopes de Souza Santos \\ Universidade de São Paulo, Brasil \\ sotosantos@uol.com.br
}

\author{
Luciano Bernardino da Costa \\ Universidade de São Paulo, Brasil \\ lbcosta45@gmail.com
}

\author{
Ruy Sardinha Lopes \\ Universidade de São Paulo, Brasil \\ rsard@sc.usp.br
}

\begin{abstract}
The article presents and discusses premises, processes and results of the workshop "Offerings - Game-performance" organized in 2015 as part of the experimental format of the III International Seminar "Representar", structured by remote and multicentric activities. The workshop faces the pervasiveness of global positioning systems (GPS) and geographic information systems (GIS) in the contemporary context, developing behavioral aesthetic works in order to update the concept of "drift" (Situacionist International) and to discuss some modes of urban perception that can be activated through the (mis)use of mobile interfaces and geolocation devices and the practice of artistic interventions in the city.
\end{abstract}

Keywords: locative media, drifting, playing, urban perception, displacement

\section{Introdução}

O artigo apresenta e discute a experiência de workshop organizado por professores do IAU-USP em 2015, como parte do $3^{\circ}$ Seminário Internacional Representar. seminário assumiu o formato de workshops como forma simultânea de ensino e pesquisa, que estimula "perspectivas críticas e revisões teórico-conceituais motivando outras tantas práticas e experiências, cuja repercussão se evidencia nas formas do ensino da Arquitetura, Urbanismo e Design, assim como na atuação profissional e na pesquisa acadêmica" (Representar, 2015a).

À luz da pervasividade dos sistemas de posicionamento global (GPS) e dos sistemas de informação geográfica (GIS) no contexto contemporâneo, a atividade teve como foco desenvolver trabalhos estéticos comportamentais com 0 objetivo de problematizar práticas atuais decorrentes do conceito de deriva (proposto pela Internacional Situacionista, na Teoria da Deriva, em 1958) e dos modos de percepção urbana que podem ser ativados por meio do uso de interfaces e dispositivos móveis de geolocalização, e de intervenções artísticas na cidade.

\section{O Workshop - aspectos institucionais}

O formato do evento, alternativo aos modelos dos congressos científicos focados em comunicações, foi composto por atividades multicêntricas e à distância, por meio da realização de workshops propostos pelas oito instituições participantes - Instituto de Arquitetura e Urbanismo e Faculdade de Arquitetura e Urbanismo, ambos da Universidade de São Paulo, Senac e Universidade São
Judas (Brasil); Faculdad de Arquitectura, Diseño y Urbanismo - Universidad Nacional del Litoral (Argentina); Facultad de Arquitectura y Urbanismo Universidad de Chile (Chile); Universidad Autonoma Metropolitana Xochimilco (México); e Faculdade de Arquitetura - Universidade de Lisboa (Portugal) -, finalizadas com uma mesa-redonda de apresentação dos trabalhos e debates por videoconferência.

No IAU-USP, localizado na cidade de São Carlos (SP Brasil), o workshop "Oferendas - Jogo-performance", com duração de dois dias consecutivos, foi proposto por pesquisadores do Núcleo de Estudos das Espacialidades Contemporâneas (NEC.USP), autores deste artigo, e pesquisadores do Núcleo de Apoio à Pesquisa em Estudos de Linguagem em Arquitetura e Cidade (N.ELAC) - Joubert Lancha, Paulo Castral e Simone Vizioli - e contou com a participação de vinte alunos de graduação e pós-graduação pré-selecionados.

\section{O Workshop - aspectos conceituais}

O objetivo principal perseguido pelo $3^{\circ}$ Representar foi o de "compartilhar experiências internacionais sobre as diferentes óticas de abordagem do problema das representações da arquitetura, do urbanismo e do design na atual conjuntura técnica e social (o mundo contemporâneo) a partir das produções acadêmicas/científicas realizadas nas Instituições universitárias. Uma abordagem que se pretende, ao mesmo tempo, experimental e didática, inquisitiva e explicativa, refletiva e propositiva, utilizando os métodos convencionais, e também as novas práticas digitais e de informação e difusão" (Representar, 2015b). 
Cada instituição-sede deveria, sob esta ótica, tomar como campo de investigação a cidade onde está inserida, a partir de dois indicativos gerais: um tema, "(Des)desenhar Fronteiras/Inaugurar Fronteiras", e uma estratégia, a "deriva".

Ao circunscrever a cidade de São Carlos como território de ação, partiu-se do desejo de expandir os meios usuais de apreensão da cidade, extrapolando as áreas da vivência cotidiana dos participantes do workshop - provindos da comunidade acadêmica da Universidade de São Paulo. Sobre o mapa de uma cidade existente há vários outros mapas, plurais, que concernem a cada grupo social e/ou habitante. Para cada um destes há uma cidade nocional, aquela que Ihe é conhecida; como há uma cidade emocional, aquela constituída pelas partes que Ihe tocam; como há também uma cidade funcional, aquela desenhada pelos fluxos cotidianos. Entre estas camadas - nocional, emocional, funcional - há sobreposições, vazios, fronteiras.

No contexto do workshop, a ação de (des)desenhar e inaugurar fronteiras na cidade de São Carlos deveria passar por extrapolar a cidade naturalizada pelo uso pragmático, ampliar a cidade nocional e encontrar novas cidades funcionais e emocionais. E, esta ação, passaria por uma problematização do significado original do ato de deriva nos dias de hoje.

Para os Situacionistas, "em uma deriva, uma ou mais pessoas durante um certo período de tempo deixam seus motivos usuais para o movimento e a ação, suas relações, seu trabalho e suas atividades de lazer, e deixam a si mesmos serem guiados pelas atrações do terreno e pelos achados que eles encontram lá... Mas a deriva inclui ao mesmo tempo este deixar-se ir e sua necessária contradição: a dominação de variações psicogeográficas pelo conhecimento e pelo cálculo de suas possibilidades." (Knabb, 1995: p. 50)

A deriva, "modo de comportamento experimental ligado às condições da sociedade urbana, técnica de passagem fugaz, através de ambientes diversos" (Internacional Situacionista, apud Careri, 2002: p. 97) devia seguir algumas regras: a existência de planejamento prévio, baseado em mapas psicogeográficos da área a ser analisada; a extensão da área, que pode ser de um quarteirão à uma cidade inteira e suas zonas periféricas; a realização em grupos; a duração de um dia, mas que pode ser ampliada para semanas ou meses (Careri, 2002). A prática estava intimamente ligada ao ato de perder-se: "Perder-se significa que entre nós e o espaço não existe somente uma relação de domínio, de controle por parte do sujeito, mas também a possibilidade de que o espaço nos domine. São momentos da vida nos quais começamos a aprender com o espaço que nos cerca (...) Já não somos capazes de outorgar um valor ou um significado à possibilidade de nos perdermos. Mudar de lugares, confrontarmo-nos com mundos diversos, ver-nos obrigados a recriar com uma continuidade os pontos de referência, tudo isso se converte em algo regenerador em um nível psíquico, ainda que na atualidade ninguém aconselharia uma experiência deste tipo. Nas culturas primitivas, ao contrário, se alguém não se perdia, não amadurecia."(La Cecla apud Careri, 2002: p.46).

Como encarar esta prática em um contexto tecnológico marcado pela hiper-geolocalização, levando-se em consideração que as tecnologias de informação, de modo particular, as mídias locativas (como smartphones integrados a GPS) vêm alterando a relação cotidiana entre sujeitos e entre estes e o espaço urbano, incrementando eficiência nos deslocamentos e localizações em detrimento das possibilidades do encontro e do imprevisto?

A artista Laura Kurgan (2013: p. 17-18) enfatiza a rede intrincada entre coordenadas e comportamentos no espaço que vem se formando, a qual utiliza como matéria de seu trabalho cartográfico: "Uma rede de relógios atômicos, câmeras e computadores construiu um globo virtual no qual cada ponto do espaço físico é facilmente coordenado com o espaço digital. (...) Nestes tempos em que coordenadas virtuais direcionam mísseis aos seus alvos e redes sociais permitiram que companhias telefônicas e outros coletores de nossos rastros de dados prevejam nosso próximo movimento no espaço físico, o expediente resultou em uma transformação radical - nós não podemos nunca estar seguros sobre qual sistema de coordenadas tem prioridade em termos de representação de nossa identidade ou de nossos movimentos espaciais."

Em formulação ainda atual, o filósofo Vilém Flusser (1985) já advertia que, diante da era da automação, o artista poderia ser reduzido a um mero funcionário dos programas quando apenas executa - mesmo que com certo grau de escolha ações neles pré-definidas. $O$ autor sinalizava, pois, a necessidade da atuação do artista (des)programando ou reinventando o jogo previsto pelos aparelhos.

Sabe-se que com a disponibilidade de equipamentos de GPS a partir da segunda metade dos anos 1990, artistas vêm traçando mapas a partir de trajetórias, utilizando sistemas que convergem redes globais, bancos de dados online e ferramentas para mapeamento baseado em localização, renovando o interesse pela ação de caminhar e cartografar como práticas estéticas (O'Rourke, 2013). Dentre outros artistas que vêm atuando neste campo, podemos citar Jeremy Wood, Esther Polak, Layla Kurtis, Christian Nold, Laura Kurgan e Manuela Costa Lima (Abrahams \& Hall, 2006; Nold, 2009; Kurgan, 2013; CostaLima, 2015)

\section{Metodologia}

Analisando-se os modos cotidianos de interação com aplicativos locativos, tais como Google Maps - e mesmo outros, focados em economia colaborativa geolocalizada, como Waze e Fouthsquare, dentre outros - permanece a seguinte lógica: busca por ponto de referência (usuário) > navegação por latitude e longitude (sistema), ou seja, a inserção de nomes de localidades é convertida em coordenadas geográficas que permitem ao sistema guiar de forma eficiente o usuário ao destino escolhido. 
No contexto do workshop, a possibilidade de encontro com o imprevisto foi trabalhada invertendo-se a lógica de input/output das mídias locativas, da seguinte forma: escolha aleatória de latitude e longitude em um intervalo determinado (usuário) > geolocalização de pontos desconhecidos pelo usuário (sistema), ou seja, a introdução de coordenadas geográficas é convertida em localidades a serem descobertas pelo usuário. Este procedimento de inversão simples, mas que se mostrou potente para desencadear a metodologia de trabalho, se articula com a noção de contramapa utilizada por Dee Morris e Stephen Voyce (2016: n.p.): "uma poética de invenção [que] pode ser utilizada não somente para apresentar formas de exploração, mas para propor formas alternativas de se pensar, sentir e viver nos mundos em que habitamos" (Morris \& Voyce, 2016: n.p.).

A partir deste princípio de inversão, a dinâmica do workshop foi então desenhada segundo princípios gerais: o formato de um jogo-performance coletivo; a ação de marcações no território; e a confecção de mapas-colagens como registros do processo. A opção pela dinâmica de um jogoperformance coletivo foi tomada como forma de enfatizar a experiência de (des)locamento e percepção da cidade como um ato compartilhado. A realização de marcações no território tomou como referência simbólica as chamadas oferendas (ofertas aos deuses, colocadas em encontro de caminhos, como forma de conexão com o sagrado em rituais religiosos), e remeteu igualmente a trabalhos de arte sitespecific, em particular Contra-bólide Devolver Terra a Terra (1979), de Hélio Oiticica, Você gostaria de participar de uma experiência artística? (1994-2016), de Ricardo Basbaum, e Message in a Bottle (2004), de Layla Curtis.

A posterior confecção de mapas-colagens foi proposta como forma de representação gráfica dos procedimentos de jogo, deslocamento e marcação vinculados às respectivas geolocalizações.

\section{Regras}

Os princípios expostos acima nortearam a criação de regras para um "jogo-performance" urbano que podem ser replicadas em outros lugares/oportunidades por outras pessoas. São elas:

1. Defina o tabuleiro: intervalo de latitudes e longitudes da região urbana onde se pretende (des)desenhar fronteiras/realizar derivas/(des)locar mídias locativas/criar fábulas.

\section{Selecione 20 participantes.}

3. Organize os participantes em um número específico de equipes, respectivo ao número de oferendas desejadas ao final do jogo.

\section{Sorteie a ordem das equipes.}

5. Cada equipe deve escolher uma combinação de latitude e longitude pertencente à região urbana do jogo como local para sua oferenda, definindo-se subsequentemente as geolocalizações $1,2,3 \ldots$

6. Munidos com dispositivos móveis de geolocalização, todos os participantes seguem à geolocalização 1. Neste local, a equipe 1 deve escolher um objeto a ele pertencente (site-specific) a ser trasladado para a geolocalização 2. Em seguida, todos os participantes seguem para a geolocalização 2 , onde a equipe 1 realiza sua oferenda (escultura implantada).

7. A etapa 5 deve ser repetida tantas vezes quanto o número de equipes no jogo.

8. A última geolocalização deverá repetir a primeira, fechando-se um ciclo.

9. Todo o ritual, os percursos, as geolocalizações e oferendas devem ser registrados por meio de mapas, fotografias e vídeos, segundo a seguinte lógica:

$$
\text { objeto } N \text { = geolocalização } N \rightarrow \text { geolocalização }(N+1)
$$

\section{Resultados}

A partir da definição do tabuleiro do jogo, um quadrado de 7 kilômetros de lado na cidade de São Carlos, e da divisão dos participantes em cinco equipes, foi realizada a escolha aleatória de latitudes e longitudes de cinco geolocalizações, ato semelhante ao do adivinho que lança búzios para revelar o desconhecido.

Em seguida, iniciou-se a "deriva" guiada entre os respectivos pontos. Utilizou-se a interface My Maps do Google para a marcação do tabuleiro do jogo e das cinco geolocalizações, - Google Maps para deslocamento pela cidade, e o Map My Run para gravação de percursos (Figura 1). O tabuleiro do jogo pode ser acessado em: https://www.google.com/maps/d/edit?mid=1bcBVu7rcKIOpw 3XmyRhysFix41I.

Dos cinco pontos referenciais definidos, apenas a primeira localização encontrava-se em uma área familiar, próxima ao campus da universidade, o Parque do Kartódromo (G1). Os outros quatro pontos localizavam-se em áreas da cidade exteriores ao cotidiano dos participantes, externas tanto ao centro, quanto ao centro expandido da cidade. O segundo ponto (Av. Faber) encontrava-se em uma área industrial na periferia da cidade (G2). O terceiro foi marcado na rua Rio Araguaia, no Jardim Jockey Club, um bairro popular às margens da Rodovia Washington Luiz, que atravessa a cidade (G3). O quarto ponto localizava-se dentro de um CDHU, conjunto de habitações de interesse social na Vila Isabel (G4). O quinto e último ponto marcava uma praça na Avenida Cesar Brigante, de onde se avista uma das regiões da expansão periférica da cidade (G5).

Enquanto um grupo atuava realizando sua coleta e outro depositava sua oferenda, os demais participantes acompanhavam e registravam as atuações, criando um elo 

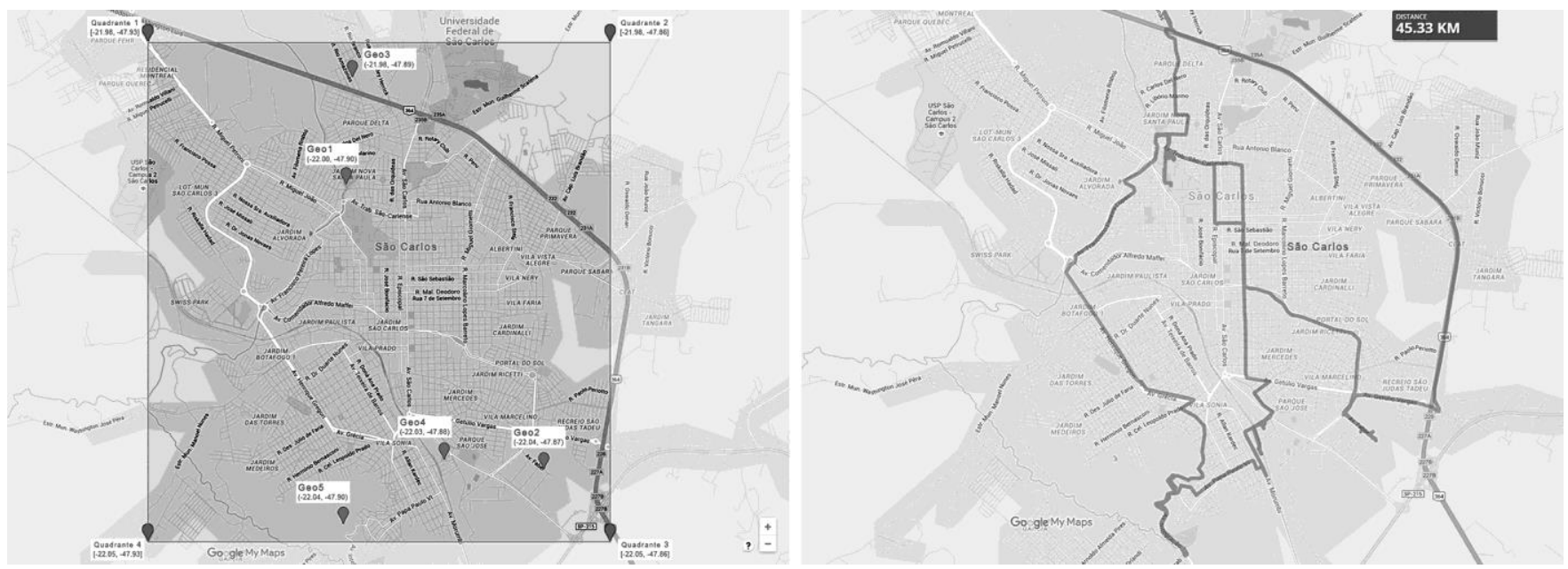

Figura 1: a) Quadrantes do Jogo (7km de distância) na cidade de São Carlos e 5 geolocalizações (latitudes e longitudes escolhidas "às cegas"); b) Trajeto realizado entre as 5 geolocalizações (Distância: 45,33km).
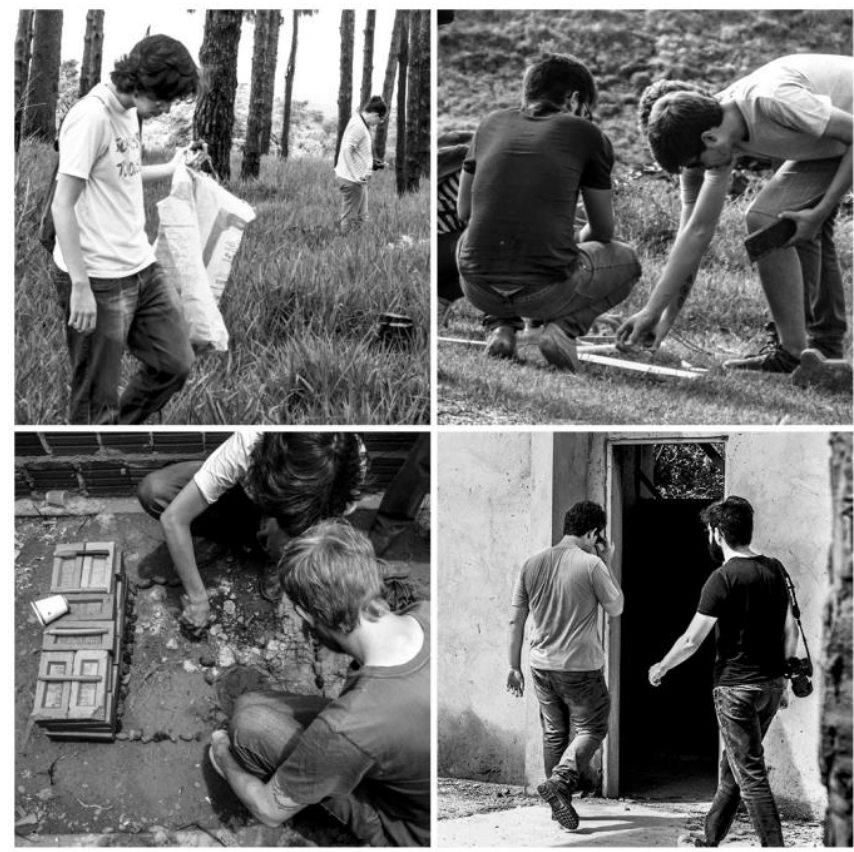

Figura 2: Dinâmica de coletas e oferendas nos pontos geolocalizados. Autor: Luciano Costa

que fazia de toda nova coleta e oferenda uma experiência compartilhada, performática, tendo o local como elemento irradiador das ações (Figura 2).

Todas essas práticas - deslocamentos, encontros, coletas, registros visuais e inscrições no território - levantaram questões sobre suas representações. O material imagético de cada par de pontos do ciclo, que corresponde a um deslocamento, foi transformado em um trabalho gráfico, um mapa-colagem, uma montagem de fotos identificada por latitudes e longitudes (Figura 3).

Descrevemos a seguir, como exemplo, a atividade desenvolvida por uma das equipes, que coletou objetos na área do Jockey Club (G3) para ofertá-los ao CDHU da Vila Isabel (G4). Na entrada do Jardim Jockey Club, bairro popular rente à Rodovia Washington, há um grande depósito de sucata; na esquina oposta há uma oficina mecânica. Ambas as empresas denotam o tipo de atividade que acontece nessa rua. $O$ trato com a sucata, o barulho dos motores dos carros; na rua, fileiras de casas térreas provavelmente construídas por seus moradores eram entrecortadas por terrenos baldios e casas em construção. Deste local, o grupo decidiu coletar como objetos representativos uma poltrona, diversos caixotes e pranchas de madeira encontradas em um dos terrenos baldios. Objetos relacionados com a prática da construção local precária.

Esses objetos foram depositados no CDHU da Vila Isabel. Nesse enorme conjunto habitacional que se estende por diversas quadras, o local que mais chamou atenção foi uma rotatória onde havia uma frondosa árvore, sob cuja sombra havia a profusão da arquitetura efêmera do comércio ambulante, carrinhos e Kombis adaptadas para vender comida, mesas e cadeiras de plástico que improvisavam um bar etc. Como oferenda, o grupo improvisou um lugar de convívio a partir da poltrona, dos caixotes e pranchas coletadas no Jardim Jockey Club.

Tal ação está representada no terceiro mapa-colagem da figura 3, geolocalização $3(-21.985,-47.899)$. Nele aparecem a poltrona e os caixotes coletados no terreno baldio, assim como aspectos da arquitetura do local. Na fileira abaixo, está representada a geolocalização $4(-22.038,-47.885)$ : registros fotográficos do comércio ambulante da rotatória do CDHU, assim como do espaço de convívio ofertado pelos alunos.

A opção pela forma de montagem das fotografias acompanhadas pelo registro exato da geolocalização procurou contrastar a exatidão dos dados com a riqueza de percepções e interpretação disparadas pelas visitas às localidades. Essa forma oscila entre a recriação da ideia de mapa, cartografia, e abertura da montagem fotográfica. 

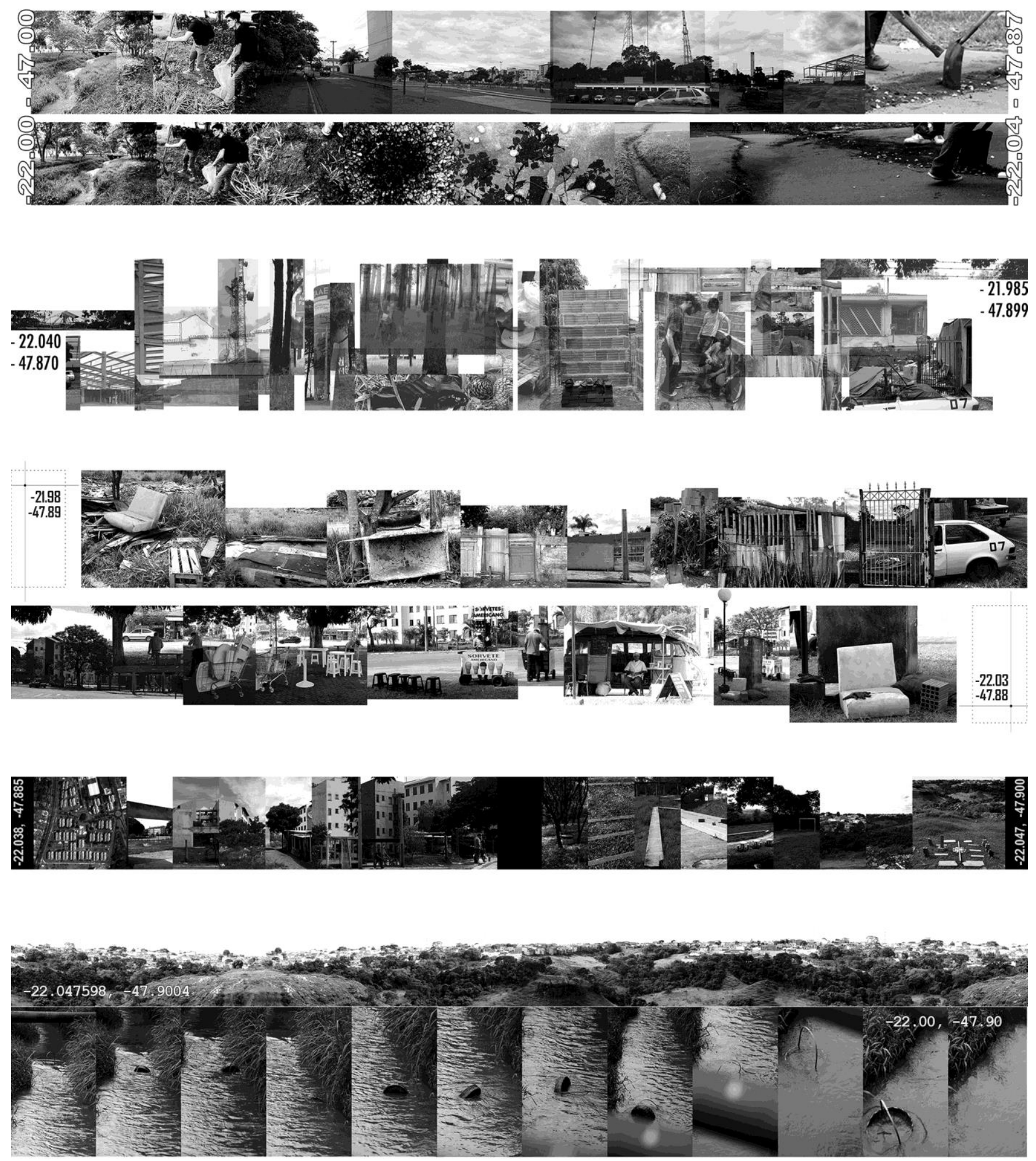

Figura 3: Mapas-colagens realizados pelos participantes a partir dos deslocamentos de objetos entre as geolocalizações (G1>G2, G2>G3, G3>G4, G4>G5, G5>G1). Autores: participantes do workshop 

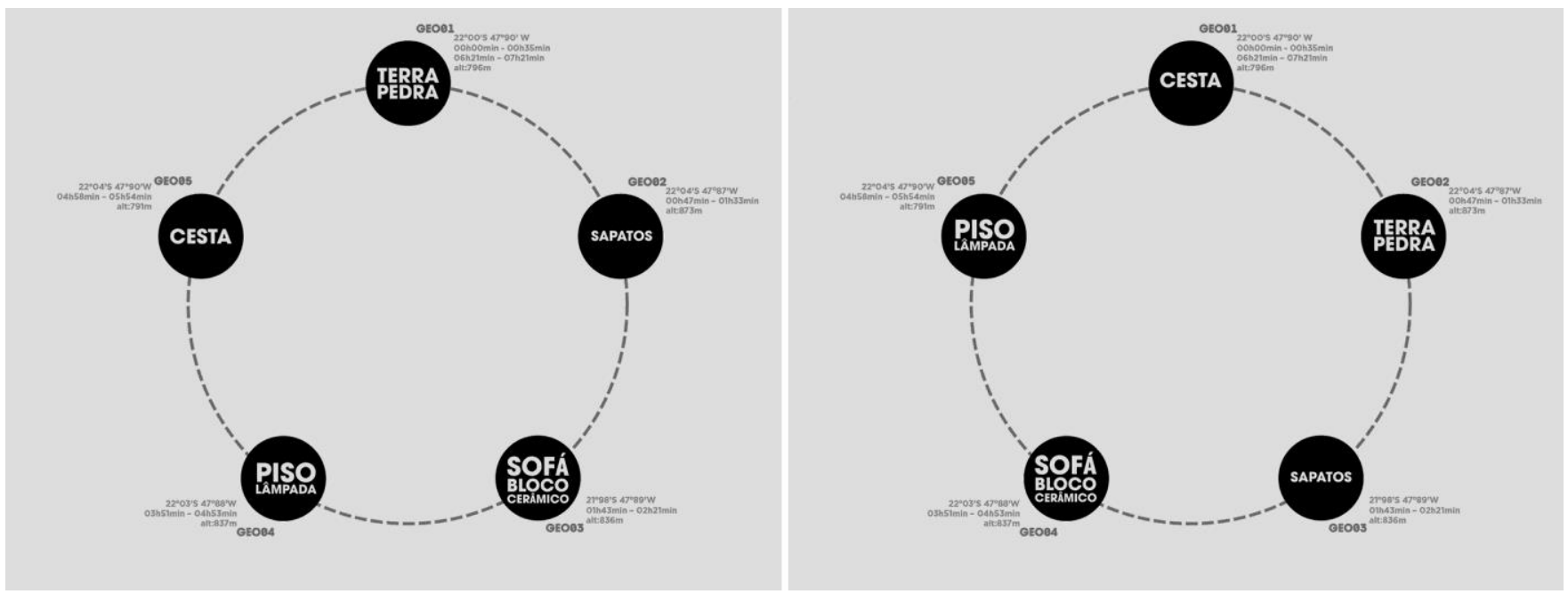

Figura 4: Diagrama do Workshop Oferendas - Jogo-performance: objetos encontrados e deslocados entre geolocalizações Gn $>$ Gn+1 (Distância: 45,33km, Tempo total: $7 \mathrm{~h} 21 \mathrm{~m}$; Intervalo de altitude: $791 \mathrm{~m}-873 \mathrm{~m}$ ). Autor: Paulo Castral

Os mapas-colagens são simultaneamente registros das ações e trabalhos plásticos em si. Permitem a observação do paralelismo e da continuidade das coletas e deposições dos objetos em outros sítios, por meio de sua reinterpretação e reelaboração gráfica. O ciclo fechado da Oferenda - jogoperformance representado pelos mapas-colagens (figura 3), pode ser visto de forma diagramática na figura 4.

O workshop se encerrou com a produção de um vídeo que compila a dinâmica, as regras, as derivas e os trabalhos produzidos, 0 qual pode ser acessado em: http://www.iau.usp.br/pesquisa/grupos/nec/index.php/videos/.

\section{Discussão}

Retomando Flusser, Arlindo Machado (2002: p.151) destacava um elo que ainda se mostra constituinte da relação entre arte e tecnologia: "O que faz um verdadeiro criador, em vez de submeter-se simplesmente a um certo número de possibilidades impostas pelo aparato técnico, é subverter continuamente a função da máquina de que ele se utiliza, é manejá-la no sentido contrário de sua produtividade programada. Talvez até se possa dizer que um dos papéis mais importantes da arte numa sociedade tecnocrática seja justamente a recusa sistemática de submeter-se à lógica dos instrumentos de trabalho, ou de cumprir o projeto industrial das máquinas semióticas, reinventando, em contrapartida, as suas funções e finalidades."

A desprogramação tática de mídias locativas efetuada no workshop mostrou-se, nesse sentido, uma ação significativa para a desnaturalização da experiência da cidade regida pelas pressões práticas do cotidiano ou induzida pelo fluxo de informações midiáticas, interfaces e dispositivos geolocativos. A inversão da lógica de uso (localização/coordenadas geográficas > coordenadas geográficas/localização) permitiu evidenciar o descompasso entre a extrema precisão dos dispositivos de georreferenciamento e sua cegueira em relação a uma série de especificidades espaciais, humanas e sociais. A inversão revelou-se eficaz para o encontro imprevisto com áreas da cidade normalmente negadas ou evitadas.

Explicitou-se, dessa forma, certa dualidade presente no uso de dispositivos de georreferenciamento: servem tanto para nos conectar de forma eficiente às áreas da cidade que frequentamos, como servem para melhor encobrir aquilo que é alheio as nossas experiências e valores. O digital não apenas nos conecta ao conhecido de forma mais eficiente, mas também pode servir para nos desconectar do indesejável e/ou do desconhecido. Se nos ajuda a saltar algumas fronteiras, reforça outras. Nesse sentido, a fluidez produzida pelo georreferenciamento marcha a contrapelo do atrito buscado e promovido pela Deriva Situacionista.

Por outro lado, a atividade de coleta de oferendas em um local visando sua posterior deposição em outro, mostrou-se útil para a aproximação aos vários locais. Uma vez que o objeto recolhido deveria sintetizar a seu modo as leituras realizadas coletivamente do local visitado, a necessidade de sua escolha obrigava os participantes a manter uma postura atenta ao local. Por mais arbitrário que fosse o objeto escolhido, ele servia como mote para a mobilização dos sentidos e do repertório dos participantes: o desconhecido sempre desponta como enigma a ser desvendado.

Um terceiro resultado (não planejado) do workshop foi o (re)encontro, não apenas entre a cidade e os participantes, mas entre esses últimos: o workshop estabeleceu uma outra dinâmica de relacionamento, extrapolando as fronteiras do cotidiano acadêmico. A descoberta da cidade, o conhecer e o fazer materializaram-se como festa, lugar do (re)encontro e da (re)conexão.

\section{Agradecimentos}

Agradecemos aos pesquisadores do Núcleo de Apoio à Pesquisa em Estudos de Linguagem em Arquitetura e Cidade (N.ELAC), professores Simone Tanoue Vizioli, 
Joubert Lancha, Paulo Castral, a José Eduardo Zanardi e aos alunos participantes do workshop: Artur da Silva Bignelli, Beatrice Volpato, Bruno Rossler, Carlos Eduardo Bruel Wellichan, Cristina Kiminami, Daniel Nardini Marques, Gabriela Farsoni Villa, Guilherme Quinilato Baldessin, Jeanne Vilela, Luis Pedro Soquetti, Mariana Tidei, Marilia Solfa, Natália Fragalle, Pablo Zuniga, Rafael Goffinet, Rafael Sampaio, Renan Leite Antiqueira, Rodrigo Nogueira Lima, Rodrigo Scheeren, Vinícius Okada D'Amico.

\section{Referências}

Abrahams, J.; Hall, P. (2006). Else/Where: mapping new cartographies of networks and territories. Minessota: University of Minessota Press.

Careri, F. (2013). Walkscapes. O caminhar como prática estética. São Paulo: GG.

Flusser, V. (1985). Filosofia da Caixa Preta. São Paulo: Hucitec.

Knabb, Ken, ed. Situationist International Anthology, Berkley: Bureau of Public Secrets, 1995.

Kurgan, L. (2013). Close Up at a Distance: Mapping, Technology, and Politics. New York: Zone Books.

CostaLima, M. (2015). Projeto Correspondência. Livro de Artista. São Paulo: Pingado-Prés.

Machado, A. (2002). Repensando Flusser e as imagens técnicas. In L. Leão (Ed). Interlab: labirintos do pensamento contemporâneo (p.147-156). São Paulo: lluminuras.

Morris, D.; Voyce, S. (2016). Counter-map collection. Recuperado de: http://jacket2.org/commentary/dee-morris-stephen-voyce

Nold, C. (2009). Emotional Cartography. Technologies of the Self. Recuperado de: www.emotionalcartography.net

O'Rourke, K. (2013). Walking and Mapping: Artists as Cartographers. Cambridge: The MIT Press.

Representar (2015a). $3^{\circ}$ Seminário Internacional "Representar 2015" (Des)desenhar (Des)Dibujar Fronteiras Fronteras / Inaugurar Fronteiras Fronteras". Recuperado de http://representar2015.blogspot.com.br/

Representar (2015b). Proposta do $3^{\circ}$ Representar. (mimeo)

Please delete this line after your work is complete. It is just a reference to maintain the graphic balance of the two columns. 